\title{
PENGARUH PERKEMBANGAN ZAMAN TERHADAP KESENIAN SINRILIK SUKU MAKASSAR
}

\section{Emanuel Omedetho Jermias, Abdul Rahman}

Universitas Negeri Makassar (UNM) Sulawesi, Indonesia

Email: emanuel1968041009@gmail.com, abdulrahman8304@unm.ac.id

\begin{tabular}{ll}
\hline INFO ARTIKEL & ABSTRAK \\
\hline Diterima & Penelitian dilakukan dengan maksud untuk mengetahui pengaruh \\
25 Oktober 2021 & perkembangan zaman terhadap kesenian sinrilik. Kesenian \\
Direvisi & merupakan buah pemikiran manusia yang melibatkan rasa/emosi \\
05 November 2021 & di dalamnya. Sinrilik merupakan sebuah kesenian yang \\
Disetujui & berbentuk sasta lisan yang dilakukan oleh orang yang disebut \\
15 November 2021 & pasinrilik. Sinrilik dimainkan dengan menggunakan alat musik \\
\hline Kata Kunci: & yang bernama kesok-kesok. Dalam penelitian ini ditemukan \\
kesenian; sinrilik; & peralihan fungsi sastra lisan sinrilik dari yang awalnya memiliki \\
perkembangan & tujuan sebagai media perantara pesan dari raja untuk rakyatnya, \\
zaman & namun seiring berkembangnya zaman sinrilik berubah menjadi \\
& media hiburan ataupun media pembawa pesan berupa nasehat \\
& dan sebagainya. Jenis penelitian yang digunakan adalah \\
& penelitian kualitatif dengan metode studi pustaka. Data yang \\
& dikumpulkan bersumber dari buku, jurnal, maupun artikel yang \\
& memiliki relevansi dengan objek penelitian. Teknik pengolahan \\
& dan analisis data yang digunakan adalah dengan mereduksi data, \\
& memaparkan data, dan membuat kesimpulan.
\end{tabular}

\section{ABSTRACT}

Studies are conducted with a view to seeing how the age development has affected the Sinrilik arts. Art is a fruit of human thought that involves the taste. Sinrilik isa oral sasrta performed by a person called the pasinrilik. The Sinrilik is played with a musical instrument called kesok-kesok. In the study the transition of the Sinrilik oral literature that originally served as a medium delivering messages from the king to his people was found, but as the age of sinrillic became either entertainment or a message medium of advice and so forth. The type of research used is qualitative research using a library study method. The Keywords: art; data gathered is generated both from books, journals, and sinrilik; development of the times articles that have a relevance to the object of research. The processing and data analysis techniques used are by reduction data, eluding data, and drawing conclusions.

$\begin{array}{ll}\text { How to cite: } & \text { Jermias, E. O., \& Abdul Rahman. (2021) Pengaruh Perkembangan Zaman Terhadap } \\ & \text { Kesenian Sinrilik Suku Makassar. Jurnal Syntax Admiration 2(11). } \\ & \text { https://doi.org/10.46799/jsa.v2i11.344 } \\ \text { E-ISSN: } & 2722-5356 \\ \text { Published by: } & \text { Ridwan Institute }\end{array}$




\section{Pendahuluan}

Menurut Kamus Besar Bahasa Indonesia (KBBI), kebudayaan adalah keseluruhan pengetahuan manusia sebagai makhluk sosial yang digunakan untuk memahami lingkungan serta pengalamannya dan yang menjadi pedoman tingkah lakunya. Manusia dan kebudayaan adalah suatu kesatuan yang tidak dapat dipisahkan. Jika tidak ada manusia, maka tidak ada pula kebudayaan. Begitu pun sebaliknya kebudayaan tidak akan tercipta jika tidak ada manusia. Koentjaraningrat berpendapat bahwa kebudayaan adalah sesuatu yang bersangkutan dengan akal dan budi. Pendapat lainnya mengatakan bahwa budaya adalah suatu perkembangan dari macam-macam budi daya yang asalnya dari kekuatan akal (Koentjaraningrat, 1993).

Indonesia merupakan sebuah bangsa yang memiliki banyak suku dan kaya akan warisan budaya. Berdasarkan data dari laman resmi Badan Pusat Statistik tahun 2010, Indonesia memiliki setidaknya lebih dari 300 kelompok suku bangsa atau 1.340 suku bangsa (Portal Informasi Indonesia, 2017). Keanekaragaman budaya yang ada di Indonesia juga ditandai dengan banyaknya peninggalan-peninggalan di berbagai penjuru Indonesia yang memiliki hubungan dengan kebudayaan.

Setiap daerah yang ada di Indonesia pada umumnya memiliki kebudayaannya masing-masing. Kebudayaan daerah sendiri merupakan kebudayaan yang terdapat pada wilayah atau daerah tertentu. Kebudayaan daerah terdiri dari gabungan beberapa suku. Kebudayaan yang berada pada daerah tertentu lebih menonjol persamaan dari pada perbedaannya. Hal ini terjadi karena suku yang berada di suatu daerah hidup berdampingan dan seringnya terjadi interaksi juga membawa pengaruh terhadap persamaan kebudayaan.

Sama halnya dengan kebudayaan, kesenian juga merupakan buah pemikiran dari manusia. Namun kesenian diciptakan dengan melibatkan "rasa" yang ada dalam diri manusia. Kesenian tidak bertumpu pada akal atau logika manusia. Kesenian bertumpu pada isi hati yang ada pada manusia.

Kesenian diinterpretasikan menurut nilai-nilai yang dianut dari manusia (Arifninetrirosa, 2005). Dengan kesenian, masyarakat dapat mengembangkan dan menciptakan sebuah kebudayaan yang baru karena kesenian itu melekat dengan masyarakat.

Contoh kesenian yang ada di Indonesia adalah tari tortor yang berasal dari Sumatera Utara. Gerakan yang ada dalam tari tortor mengikuti irama dari iringan musik. Penari tortor pun turut mengikuti suasana yang dihadirkan dari musik pengiring. Alunan gerakannya dapat menjadi lembut dan dapat menguraikan air mata. Hal itu memiliki makna adanya keseimbangan antara suka dan duka (Melalatoa, 2014).

Dari sekian banyaknya kesenian yang ada di negeri dengan kekayaan alam yang melimpah ini, ada kesenian daerah yang masih dijaga dan dilestarikan hingga sekarang. Namun ada pula kesenian daerah yang lambat laun dilupakan seiring dengan berkembangnya zaman. Berkembangnya zaman ke arah yang lebih modern dapat menurunkan minat masyarakat terhadap kesenian yang sudah diciptakan dari dulu kala (Suneki, 2012). Adapun alasan yang sering dijumpai yaitu kesenian (dalam hal ini yang 
dimaksud adalah kesenian daerah) dianggap sebagai suatu hal yang sudah lawas atau kuno dan sudah tidak relevan dengan situasi masa sekarang ini.

Makassar adalah salah satu dari sekian banyak kota yang ada di Indonesia yang memiliki wilayah seluas $128,18 \mathrm{~km}^{2}$. Dalam penulisan sejarah Sulawesi Selatan pada abad ke-16 hingga ke-17, Kerajaan Makassar (Gowa-Tallo) mencapai puncak kejayaannya dan bahkan menjadi periode yang paling menyita perhatian peneliti dan penulis sejarah (Makkelo, 2020). Selain menjadi ibu kota dari provinsi Sulawesi Selatan dan sebuah kotamadya, makassar juga merupakan sebuah suku layaknya suku lain yang ada di kota makassar diantaranya suku Bugis, Toraja, Mandar, Buton, dan lain-lain.

Kota Makassar atau yang biasa dieja Macassar atau Mangkasar yang dimulai dari tahun 1971 sampai pada tahun 1999 secara resmi dikenal sebagai Ujungpandang. Kota Makassar terletak pada titik 5 ${ }^{\circ} 8^{\prime} \mathrm{S} 119^{\circ} 25^{\prime} \mathrm{E}$ Koordinat: $5^{\circ} 8^{\prime} \mathrm{S} 119^{\circ} 25^{\prime} \mathrm{E}$, di pesisir barat daya pulau Sulawesi yang berseberangan dengan Selat Makassar. Totalnya makassar memiliki 14 kecamatan, 143 kelurahan, 885 RW dan 4446 RT Secara geografis, kota Makassar berada sekitar 0-25 meter di atas permukaan laut dan dihimpit oleh Sungai Tallo dan Sungai Jeneberang. Menurut laman resmi dari Pemerintah Provinsi Sulawesi Selatan tahun 2008, dikatakan bahwa jumlah penduduk yang ada di kota Makassar sebanyak 1,253,656 jiwa (Badan Pusat Statistik Kota Makassar, 2009).

Diantara sekian banyaknya penduduk yang tinggal dan hidup di kota Makassar, ada beragam kesenian yang tampak dan masih dapat kita jumpai hingga sekarang ini. Contohnya seperti Tari Pakkarena dan Tari Empat Etnis yang merepresentasikan budaya Makassar, Bugis, Toraja dan Mandar. Contoh lain dari kesenian yang ada di Makassar adalah tari Gandrang Bulo. Gandrang Bulo merupakan sebuah kesenian yang menggabungkan antara musik, tarian, dan dialog yang berisi lawakan untuk membuat para penontonnya tidak hanya terpuakau oleh bentuk estetika yang dihadirkan, namun ikut terhibur oleh dialog-dialog dalam tari Gandrang Bulo tersebut (Sidin, n.d.).

Makassar memiliki banyak kesenian yang masih lekat pada masyarakatnya hingga pada saat ini. Beberapa contohnya seperti yang sudah dipaparkan di atas. Namun dari sekian banyaknya kesenian yang ada di Makassar ini, beberapa diantaranya mengalami perubahan. Entah itu dari segi penayangannya atapun faktor-faktor yang lainnya. Salah satu contohnya seperti ganrang tallua (gendang tiga). Ganrang tallua merupakan musik iring-iringan yang ditampilkan pada saat pernikahan yang terletak di desa Toddolimae, Kecamatan Tompobulu, kabupaten Maros. Alat musik ini dimainkan tanpa adanya alat musik pengiring lain, namun seiring berjalannya waktu, ganrang tallua mengalami beberapa perubahan seperti adanya alat musik lain yang turut dimainkan dengan ganrang tallua dalam prosesi perkawinan daerah tersebut (Rizaldi et al., 2018).

\section{Metode Penelitian}

\section{Jenis Penelitian}

Jenis penelitian yang dilakukan adalah studi pustaka. Menurut (Stefanus, 2013), Jenis penelitian ini merupakan jenis penelitian pendeskripsian yang lebih memusatkan data-data dari berbagai buku, jurnal, maupun artikel yang relevan 
dengan objek penelitian sebagai sumber analisisnya. Adapun tujuan dari penelitian yang dilakukan ini adalah untuk mengetahui apakah perkembangan zaman turut mempengaruhi kesenian sinrilik yang ada di suku Makassar.

\section{Metode Pengumpulan Data}

Menurut (Mestika, 2014) ada beberapa hal yang dapat menjadi pusat perhatian peneliti dalam melakukan metode studi pustaka, yaitu: (1) data yang peneliti miliki bersumber dari teks atau data angka dan bukan bersumber dari lapangan; (2) data yang dimiliki oleh peneliti sudah siap untuk digunakan sehingga membuat peneliti sudah tidak perlu melakukan penelitian secara langsung kepada objek penelitian; (3) data yang peneliti miliki umumnya adalah data yang sudah tidak orisinil dari objek penelitian dikarenakan data yang dimiliki tidak bersumber langsung dari objek penelitian; (4) data yang ingin dikumpulkan oleh peneliti bisa didapatkan dari mana saja (baik yang memiliki fisik seperti buku maupun media online). Peneliti dapat mengumpulkan data dengan cara melakukan pengkajian dari sejumlah sumbersumber data atau informasi yang relevan dengan objek penelitian (Supriyadi, 2016). Setelah data-data yang ada sudah terkumpul, selanjutnya peneliti melakukan generalisasi pada data yang ada agar mendapatkan hasil final dan dapat mengeluarkan sebuah kesimpulan (Darmalaksana, 2020).

Teknik pengolahan dan analisis data yang digunakan dalam penelitian ini adalah dengan cara mereduksi data, memaparkan data, dan membuat kesimpulan (Miles \& Huberman, 1992). Reduksi data berarti data yang sudah dikumpulkan dari sumber-sumber terkait dengan objek penelitian dipilah dan disaring agar data-data yang terkumpul dapat sesuai atau tidak keluar dari tema yang diangkat dalam penelitian. Setelah tahap mereduksi data, kemudian dilanjutkan dengan tahap pemaparan data. Pemaparan atau penyajian data merupakan tahap dimana data-data yang telah rampung dimasukkan sesuai dengan sub bab data tersebut. Tahap terakhir adalah tahap kesimpulan. Tahap kesimpulan atau verifikasi merupakan tahap dimana penulis mendalami data-data yang diperoleh untuk dicari makna, keselarasan, dan hubungan sebab akibat yang dimiliki data tersebut (Nurkumala, 2013).

\section{Hasil dan Pembahasan}

\section{Penjelasan Mengenai Sinrilik}

Sinrilik adalah sebuah tradisi sastra lisan yang berbentuk prosa lirik. Sinrilik merupakan sebuah cerita yang disusun dengan memasukkan unsur puitis di dalamnya dan diutarakan dengan cara berirama oleh seorang ahli yang disebut pasinrilik (Nasruddin et al., 2007). Dalam mengutarakan ceritanya, umumnya seorang pasinrilik tidak membaca teks ataupun sebuah bacaan, namun seorang pasinrilik menghafalkan isi cerita yang ingin ia utarakan (Nasruddin et al., 2007).

Berdasarkan cara pelantunannya, Sinrilik terbagi menjadi dua yaitu sinrilik pakesok-kesok dan sinrilik bosi timurung. Sinrilik pakesok-kesok adalah jenis sinrilik yang isi ceritanya tentang kepahlawanan dan diiringi dengan alat musik pakesokkesok. Pakesok-kesok sendiri adalah sebuah alat musik yang terbuat dari kayu dan 
memiliki dua senar. Bentuk dan cara menggunakan alat musik ini hampir sama dengan biola, yaitu dengan cara digesek. Namun yang menjadi perbedaan dengan biola adalah kesok-kesok tidak dimainkan di bagian bahu pemainnya, namun diletakkan di tanah/permukaan bersama dengan pemainnya. Dan juga kesok-kesok dimainkan mengikuti irama yang dilantunkan oleh sang pasinrilik.

Jenis kedua dari sinrilik yaitu sinrilik bosi timurung. Sinrilik bosi timurung dalam bahasa Makassar memiliki arti "hujan turun". Lantunan sinrilik ini tidak diiringi dengan alat musik. Pasinrilik hanya melantunkan iramanya sendiri saja. Isi cerita yang dibawakan oleh pasinrilik tidak panjang dan mengandung unsur kesedihan di dalamnya. Isi cerita sinrilik bosi timurung umumnya adalah curahan hati sang pasinrilik (Wikipedia, n.d.).

Sebagai sebuah bentuk kesenian prosa lirik, sinrilik juga memiliki gaya bahasanya sendiri. Dalam buku (Parawansa et al., 1992), ada beberapa jenis gaya bahasa yang digunakan seorang pasinrilik dalam menuturkan ceritanya. Beberapa contohnya yaitu dengan menggunakan gaya personifikasi, gaya antiklimaks, maupun gaya ironi. Berikut contoh penggunaan gaya antiklimaksnya yaitu:

"kasipalli lonna 'muko. harangi na lekbak-lekbak, napannyongkangi punna lonna sakorolo, annememang kamma-kamma"

Yang berarti:

"pamali kalau besok. haram kalau sebentar, dia tolak kalau tunggu dahulu, harus sekarang juga"

Selain memiliki gaya bahasanya, sinrilik juga memiliki nilai-nilai yang terkandung dalam isi cerita atau isi penyampaiannya. Salah satu di antaranya adalah nilai religius. Nilai religius dapat ditemukan dalam sinrilik bosi timurung I 'Balu'. Salah satu nilai religius yang dimaksudkan adalah nilai Mempercayai Kebesaran Tuhan. Dalam sinrilik bosi timurung I 'Balu' dapat dimaknai bahwa setiap manusia pasti memiliki rencana atau kemauannya masing-masing, namun Tuhanlah yang akan memilih jalan hidup dari setiap manusia ciptaan-Nya (Nurhaedah \& Amir, 2021).

\section{Sinrilik Pada Masa Lampau}

Pada beberapa daerah di masa lampau, pasinrilik menyandang status tertentu di mata masyarakat. Pasinrilik diberikan sebidang tanah persawahan dari penguasa setempat sebagai sumber mata pencaharian mereka. Adapun masyarakat yang sudah memanggil pasinrilik biasanya memberikan sesuatu dengan cara adat tertentu (Parawansa et al., 1992).

Pada zaman pemerintahan di Gowa, sinrilik merupakan sebuah media perantara pekabaran yang menghubungkan antara raja Gowa dengan rakyatnya. Jadi pada saat raja Gowa ingin menyebarkan informasi kepada rakyatnya, maka sang raja akan memanggil pasinrilik untuk menyebarkan informasi tersebut. Begitu pun rakyat Jika rakyat ingin menyampaikan suaranya kepada sang raja, maka rakyat pun akan memanggil pasinrilik untuk menyampaikan informasi tersebut kepada raja. Mulai saat itu sinrilik akhirnya bertumbuh menjadi media sastra tutur yang berisi pendidikan, nasehat, kritik, arahan untuk mengatur tingkah laku manusia berdasarkan 
norma, maupun hanya sebagai hiburan atau semata-mata hanya menyampaikan informasi (Machmud, 2011).

\section{Perkembangan Kesenian Sinrilik}

Seiring dengan berkembangnya zaman, kesenian sinrilik juga mengalami beberapa perubahan. Jika pada masa pemerintahan Gowa seorang pasinrilik memiliki status dalam lingkungan masyarakatnya, namun seiring berkembangnya zaman, hal tersebut sudah mulai pudar. Berdasarkan data hasil wawancara dari buku (Parawansa et al., 1992), dari total 20 orang pasinrilik semuanya memiliki pekerjaan yang beragam. Pekerjaan yang paling banyak dilakukan yaitu sebagai petani (sebanyak 12 orang). Sisanya ada yang bekerja sebagai nelayan, penjual ikan, dan beberapa lainnya.

Demikian pula dengan hasil wawancara yang dilakukan oleh (Machmud, 2011). Dalam hasil wawancaranya dengan salah seorang masyarakat yang tinggal di Kabupaten Gowa, Machmud mengatakan bahwa kesenian sinrilik berkembang menjadi media hiburan dan kadang pula menjadi pembawa acara dalam sebuah acara yang diselenggarakan. Peralatan pendukung yang digunakan untuk menampilkan kesenian sinrilik pun ikut berkembang seiring zaman. Jika dulunya sinrilik hanya ditampilkan di tempat yang sederhana tanpa adanya alat pendukung ataupun panggung, maka perkembangan zaman membuat kesenian sinrilik kini memerlukan media pendukung lainnya dalam penampilannya seperti pengeras suara ataupun sebuah panggung (Machmud, 2011).

\section{Kesimpulan}

Sebagai sebuah kesenian asli Makassar yang sudah ada sangat lama, sinrilik ikut bertumbuh seiring dengan perkembangan zaman. Mulai dari hanya sebatas media perantara yang digunakan oleh raja kepada rakyatnya, kemudian bertumbuh menjadi sebuah media yang memiliki banyak peran seperti memberi nasehat, kritik, dan masih banyak lagi.

Media penyebaran kesenian sinrilik juga ikut berkembang seiring dengan berkembangnya zaman. Jika pada masa lampau sinrilik hanya dapat ditampilkan secara langsung oleh seorang pasinrilik, maka dengan berkembangnya zaman dan dengan adanya media komunikasi sekarang ini, kesenian sinrilik dapat dinikmati kapan saja dan dimana saja. 


\section{BIBLIOGRAFI}

Arifninetrirosa. (2005). Pemeliharaan Kehidupan Budaya Kesenian Tradisional dalam Pembangunan Nasional. Jurnal USU Repository Universitas Sumatera Utara, 6. Google Scholar

Badan Pusat Statistik Kota Makassar. (2009). Makassar dalam Angka 2009 (Seksi Integrasi Pengolahan dan Diseminasi Statistik (ed.)). Badan Pusat Statistik Kota Makassar. Google Scholar

Darmalaksana, W. (2020). Metode Penelitian Kualitatif Studi Pustaka dan Studi Lapangan. Pre-Print Digital Library UIN Sunan Gunung Djati Bandung, 1-6. Google Scholar

Koentjaraningrat. (1993). Kebudayaan Mentalitas dan Pembangunan (16th ed.). PT Gramedia Pustaka Utama. Google Scholar

Machmud, M. (2011). Komunikasi Kearifan Lokal Etnis Makassar. Jurnal Salam, 14 (2), 1-14. Google Scholar

Makkelo, I. D. (2020). Sejarah Makassar dan Tradisi Literasi. Lembaran Sejarah, 15(1), 30. https://doi.org/10.22146/lembaran-sejarah.59523. Google Scholar

Melalatoa, M. J. (2014). Kesenian Indonesia. Antropologi Indonesia, 0 (62), 6-8. https://doi.org/10.7454/ai.v0i62.3390. Google Scholar

Mestika, Z. (2014). Metode Penelitian Kepustakaan (3rd ed.). Yayasan Pustaka Obor Indonesia. Google Scholar

Miles, M., \& Huberman, M. (1992). Analisis data kualitatif: buku sumber tentang metode metode baru. Penerbit Universitas Indonesia (UI -Press). Google Scholar

Nasruddin, Jemmain, Mustafa, Rasyid, A., Rijal, S., I, J., Djirong, S., \& Syahril, N. (2007). Bunga Rampai: Hasil Penelitian Bahasa dan Sastra. In D. Sugono, Z. Hakim, A. Usmar, A. Rasyid, \& J. I (Eds.), Angewandte Chemie International Edition, 6 (11), 951-952. Departemen Pendidikan Nasional. Google Scholar

Nurhaedah, S., \& Amir, J. (2021). Nilai-Nilai Religius yang Terkandung dalam Sinrilik Bosi Timurung I 'Balu.' 28-37. Google Scholar

Nurkumala, S. (2013). Pelaksanaan Fungsi Rekreatif pada Layanan RBM (Ruang Belajar Modern) dalam Meningkatkan Minat Kunjung Pemustaka di Perpustakaan Daerah Provinsi Jawa Tengah. In Institutional Repository (UNDIP-IR) (Issue). Diponegoro Univerrsity. Google Scholar

Parawansa, P., Wahid, S., Basang, D., Johari, A., \& Hamzah, M. (1992). Sastra Sinrilik Makassar. Pusat Pembinaan dan Pengembangan Bahasa Departemen Pendidikan dan Kebudayaan. Google Scholar 
Portal Informasi Indonesia. (2017). Suku Bangsa. https://indonesia.go.id/profil/sukubangsa/kebudayaan/suku-bangsa\#: :text=Indonesia memiliki lebih dari 300,mencapai 41\%25 dari total populasi. Google Scholar

Rizaldi, R., Manda, D., \& Dahlan, M. (2018). Seni Tradisional Ganrang Tallua di Desa Toddolimae Kecamatan Tompobulu Kabupaten Maros. Universitas Negeri Makassar. https://scholar.google.com/citations?view_op=view_citation\&hl=en\&us er=9FvT0BcAAAAJ\&pagesize $=100 \&$ citation_for_view=9FvT0BcAAAAJ:dhFuZ R0502QC. Google Scholar

Sidin, N. (n.d.). Eksistensi Gandrang Bulo Budaya di Kampung Paropo Kota Makassar. 1, 12. Google Scholar

Stefanus, G. (2013). Analisis Deskriptif Faktor-Faktor Yang Memengaruhi Kenyamanan Membaca Pemustaka (Studi Kasus Pemustaka di UPT Perpustakaan Politeknik Negeri Semarang) [Diponegoro University]. In Institutional Repository (UNDIP-IR). Google Scholar

Suneki, S. (2012). Dampak Globalisasi Terhadap Eksistensi Budaya Daerah. II (1), 307-321. Google Scholar

Supriyadi. (2016). Community of Practitioners: Solusi Alternatif Berbagi Pengetahuan antar Pustakawan. Lentera Pustaka: Jurnal Kajian Ilmu Perpustakaan, Informasi Dan Kearsipan, 2 (2), 83-93. Google Scholar

Wikipedia. (n.d.). Sinriliq. Retrieved October 17, 2021, from https://id.wikipedia.org/wiki/Sinriliq. Google Scholar

\section{Copyright holder:}

Emanuel Omedetho Jermias, Abdul Rahman (2021)

First publication right:

Jurnal Syntax Admiration

This article is licensed under:

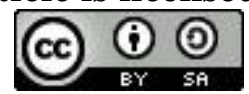

